\title{
Haptic Mediations
}

\section{Intergenerational Kinship in the Time of COVID-19}

\section{Bob Simpson}

\begin{abstract}
Aвstract: During the COVID-19 crisis, living in lockdown and observing social distancing rules have become an integral part of everyday life. In this article, I offer some autoethnographic reflections on the increased use of ICTs within families and particularly across generations. Using vignettes relating to communication with my one-year-old granddaughter and my 92-year-old mother, I consider what it means to have the haptic dimensions of kinship relations stripped out and replaced by technologically mediated connection. By way of conclusion, I consider the relationship between the 'magic' of ICTs in interpersonal communication on the one hand and Marshall Sahlins' notion of mutuality on the other.
\end{abstract}

KeYwords: communication, COVID-19, haptics, ICTs, kinship, lockdown, social distancing, touch

In recent months, two new words have acquired widespread use in Anglophone worlds: 'lockdown' and 'social distancing'. The former refers to prolonged confinement, usually in the home, and the latter to a self-imposed cordon sanitaire of between one or more metres between people. Both refer to measures that are intended to prevent the spread of the coronavirus by reducing the occasions on which person-to-person transmission might take place. The prescriptions for limiting contagion would seem to be straightforward. Their social and behavioural implications, however, are much more complex, as these simple instructions impinge upon the most fundamental aspects of our relationships with others and especially those that fall in that dense domain of mutuality, obligation and affect that we think of as kinship.

In this article, I want to reflect on some of these implications for the practice and expression of intergenerational kinship relations. I do this by way of a brief exercise in auto-ethnography. I am a 63-year-old, who, by comparison with the majority in the United Kingdom, is economically and technologically privileged. From this position, I want to consider aspects of my relationship with a one-year-old grandchild at one end of my thinking and a 92-year-old mother at the other. My wife and I have been unable to have any physical contact with these most significant of others for three months at the time of writing.

First, however, let me address a semantic confusion that stems from the idea of social distancing, which, in reality, is nothing of the sort; it is physical distancing that we are being implored to observe. The distinction is critical. The semantic slippage obscures the fact that the COVID crisis has merely accelerated a revolution in the switch from physical interactions to ones that are mediated by information and communication technologies (ICTs). For example, a common refrain throughout the crisis has been 'thank goodness for ... FaceTime, WhatsApp, Messenger, Skype, Zoom, etc.'. Advice by local authorities, the NHS (National Health Service) and support organisations such as Age UK and Dementia UK all emphasises the importance of - and the metaphor is worthy of note - 'keeping in touch', and there is widespread advocacy of the use of ICTs in order to do so. My computer support man tells me that he is busier than ever servicing and updating home- 
computing needs. He says that demand for screens, phones and cameras has rocketed and that prices have risen sharply as supply chains from the far East have dried up. Furthermore, at this time, many have experienced a sudden absence of work and a corresponding decompression of time as normal routines of daily life are dissolved.

During this newly available time, social relations, far from being severed by the lockdown, have for many become rather more intensified. Physical proximity on the other hand, and the occasions when people might touch, hold and physically 'be' with one another, have been significantly reduced and for some removed altogether. Back in the 1980s, Ashley Montagu opined in the preface to the $3^{\text {rd }}$ edition of his classic work 'Touching' that: 'We in the Western world are beginning to discover our neglected senses. This growing awareness represents something of an overdue insurgency against the painful deprivation we have suffered in our technologised world' (1986: $3)$. It would seem that in the time of COVID our 'neglected senses', far from being a rallying point for an insurgency, are the subject of a massive technological colonisation. Yet, what does it mean to strip out the non-verbal, and specifically the haptic, from that multifaceted engagement between one person and another which is human sociality?

The word 'haptic', it turns out, is also a somewhat recent addition to popular discourse. It is derived from the Greek haptesthai, meaning 'to touch', and is currently gaining wide currency via the worlds of phone communication, video gaming and robotics. My phone, for example, has an option to switch 'haptics' on and off. Essentially, newer phone models now have the capability to replace visual and verbal cues with tactile ones, that is, by various buzzes and vibrations. At their most complex, haptic technologies involve the simulation of manoeuvres which add physical sensation to the experience of virtual reality. Here we are on the road to what David Howes (2004) has referred to as 'hyperesthesia', the enhancement of commodities and the experience of consumption by elaborating their sensory dimension. No doubt, someone in the R\&D Department of an ICT company is at this moment trying to figure out how to deliver a haptic hug via a virtual reality headset and gloves.

The term 'haptic', however, has a longer and rather more erudite pedigree than its recent use to help market advancing ICT capability. In psychology and physiology, what is known as the 'haptic system' links the external environment with the internal body by means of kinaesthesia (the sense of movement), proprioception (felt muscular position) and the vestibular system (the sense of balance). The cutaneous layer in which we find ourselves bound is of great significance in the haptic system; it is the most elementary of organs and the one that gives us many of our primary experiences of being in a world - a world that is not merely physical but thoroughly social. Here, think of the neonate's experience of being nursed, stroked, held, fed and immersed in the bodily warmth of others. These experiences are critical in human development and go on being so. They have a particularly important role in the expression of care and compassion in the face of illness and distress, as touch triggers the release of endorphins, hormones that help promote well-being as well as dulling pain. The physiological and evolutionary story of touch amongst humans is well rehearsed and documented (e.g. see Montagu 1986). This story is complemented by an extensive literature that elaborates how the basic sensorium in general, and touch in particular, varies under different cultural, historical and economic conditions (Howes 2014, 2018; Howes and Classen 2014). Within societies, there is also variation, as protocols and etiquette determined by culture, age, gender and social class define who, when, how and where on the body one person might touch another in the act of showing sentiments such as kindness, care, compassion, solidarity and affirmation. Whilst accounts of the significance of touch and the various forms that it takes are widely available in this literature, what is less evident are considerations of its attenuation within the thickened mutuality of family and kin, where the expectation of haptic engagements is likely to be high. Let me use some examples from my own recent experience to make the point.

Our younger daughter [age 35] lives in Glasgow with her partner on the third floor of a west end tenement. When the lockdown began, their daughter was nearly 11 months old. Since her birth, we have all been physically together at least once a month either at their home in Glasgow or ours in Durham. As grandparents, co-presence is important to us, and we are quite 'hands on'. There is a deep and primal delight in the physicality of contact, just as there was with our daughters when they were small. The lockdown means that we have been deprived of this physical contact, and it is felt as a loss and a frustration. What we have had however, is daily FaceTime communication and a deluge of images and video clips on WhatsApp. In these, we are getting far more of a sense of our granddaughter's development than we would otherwise have had. She seems comfortable with the technology and grammar of its images (Figure 1). We can play 'hide-peepo', and she can 


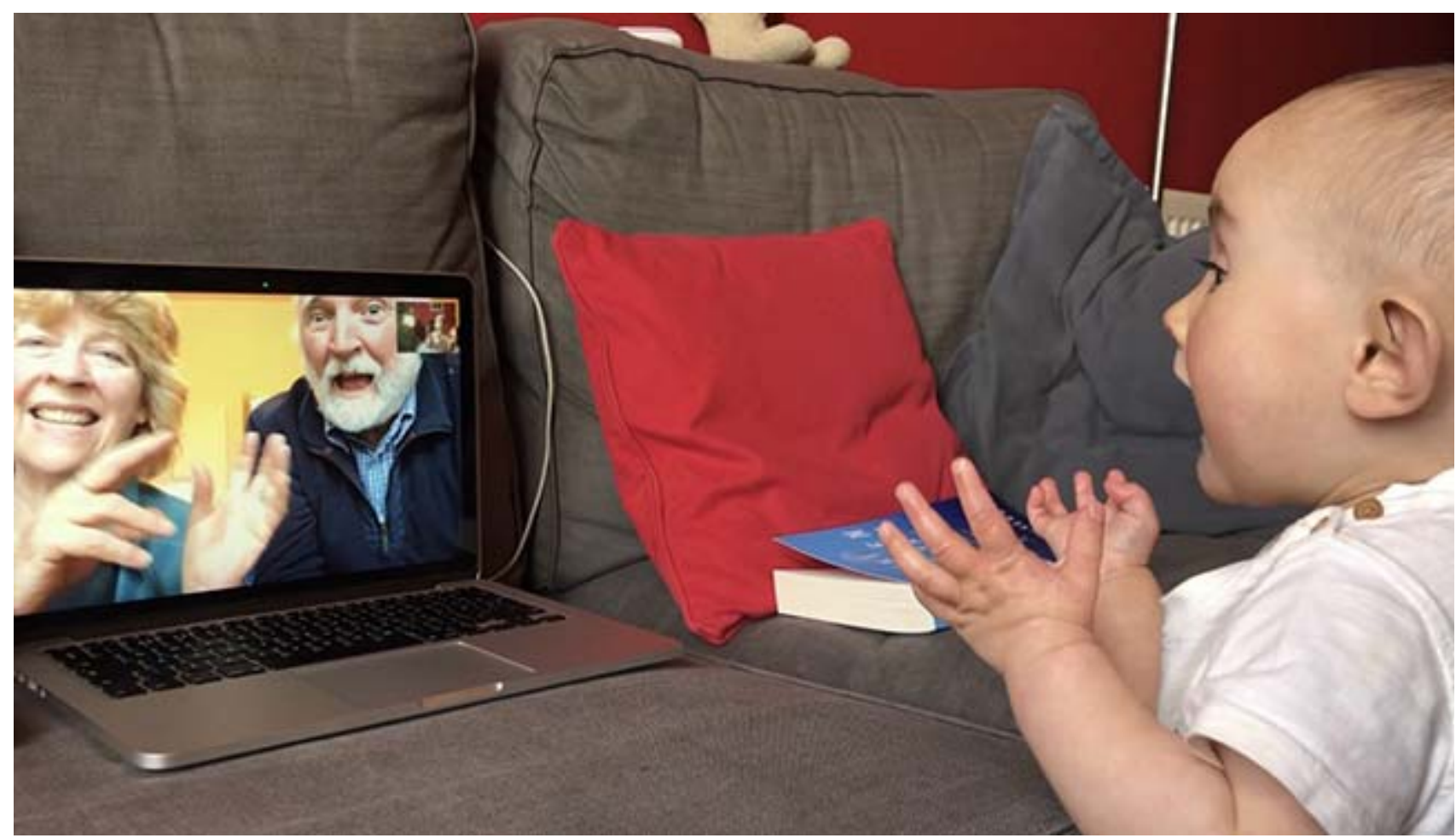

Figure 1. Bob and Joanna converse with their one-year-old granddaughter over the Internet.

show us her books and her latest developmental milestones. This has included her early efforts at bipedalism, her emerging speech, and the beginnings of a person with a sense of others and of herself in relation to them.

Although we might be feeling deprived of haptic nourishment at this time, this is far from the case for her. She has not had contact with other adults and children in this time, but during a period of intensified familial nucleation she has had a level of physical contact with, and attention from, both her parents that she would not have had were it not for the lockdown. For our daughter and her partner, as for many others, in the current enforced cocooning there dawns a realisation of a slower, more caring and more intimate way of being together. Alternatively, where parents and children are living in unhappy relationships, lockdown might generate 'touch' that is not about signalling care or intimacy but abuse and control.

At the other end of the generational continuum is my 92-year-old mother living in semi-sheltered accommodation in Manchester. She is very deaf and not very mobile, but she is hanging on determinedly to her independence. Before lockdown, we made trips down to see her once every couple of months. A few hours were usually all she could manage, but it was enough time to hold hands, hug, reminisce and share some food together. Just before the lockdown was announced, she was deteriorating quite rapidly. She was becoming more confused, and her legs were badly swollen with oedema. We, my two siblings and I, were beginning to discuss a move to a care home, what the options were and how it might be managed; when the lockdown hit, any thought of a move became impossible. On our last visit to her in the week before the 'stay at home' message, her discomfort was palpable and even the smallest of actions needed great effort. At one point, she was lying in her bed and she reached out to take my hand. She held it tightly and looked at me directly - 'my little boy', she said, and after a pause, 'thank you'. Gripping her hand all the more tightly, I protested: 'Mother, it is me that should be thanking you'. Shortly after, I went out of the room, shuddering with emotion. I felt then that this was possibly the last meaningful, physical exchange I would have with her. Following the lockdown, my sister, who lives close by my mother, stepped up her role as her primary carer, tending to her on a daily basis. Doctors and nurses visited and gradually, and very much against the odds, the swelling in her legs reduced and she recovered some of her quality of life (Vitamin D supplement seems to have played a significant role on this, but that is 
another story). At the time of writing, I still have not had physical contact with her and direct communication is impossible. She is too deaf to use a phone, and my sister falls on the wrong side of the digital divide, so communication is limited to occasional texts and updates. I write letters in big fonts in the hope that my mother can read them but knowing that she would not be able to write back. As lockdown restrictions eased, my brother paid my mother a visit and was able to set up a FaceTime call. The incoming call was unannounced, and it was a shock to see her after over three months. My sister had done my mother's hair, and although she looked very frail, she looked surprisingly well. However, despite shouted explanations and much finger pointing at the tiny heads on the screen, she could not see past the piece of technology my brother held in front of her: 'That must have cost a packet?', 'Can they see me?', 'Who is that in the corner?', 'Is that our Robert?', 'Isn't it marvelous?'. We managed to progress as far as waving to one another but little further before she seemed to become uninterested in the miracles of modern ICTs.

By way of conclusion to this somewhat personal reflection on haptics and intergenerational kinship, I would like to offer a reflection on the relation between magic and mutuality. ICTs usher in a world of magic - that is to say, we easily accept that seeing is the extent of our believing. The illusion that we embrace is that we are watching people who are just on the other side of a screen rather than an assemblage of currents, circuits and pixels that is separating us. What the trompe l'oeil renders invisible are the global corporations, the finance networks, global labour markets, component supply chains, and the ways in which resources are extracted and exploited in creating this assemblage. What is also rendered invisible in the current headlong rush into computer-mediated sociality are major security and data protection issues. The price of 'keeping in touch' has been a mass rendering up of personal 'data' and a quantum leap in the extent to which trust is now placed in global and state interests to manage it in ways that are consistent with democracy. The enchantment also transforms the experience of relationships. The easy communication that ICTs make possible strips out much of the physical and social complexity that physical co-presence generates. It invites us to replace actual relations for technologically mediated connections. The distinction between connection and relation is critical (see Strathern 2020).

Let me elaborate by way of Sahlins' notion of mutuality. This term was placed at the centre of his attempts at a wholly cultural (that is, not genealogi- cally grounded) account of human kinship (Sahlins 2013). The term is used to capture the ways in which people think of themselves as being 'intrinsic' (Sahlins 2013) to one another's sense of being, rather than merely held together by 'relations' that are defined according to criteria that are outwith their particular culture and context. In this regard, my previous auto-ethnographic vignette reveals something of the particularities of my own experience of kinship. The sense of people who think of themselves as belonging to or possessing, one another might be glimpsed in my mother's use of the possessive vernacular 'our Robert'. Yet, in the accelerated move to ICT-mediated communication between the generations, what is the fate of this kind of mutuality? I have the question but not the answer. But it is clear that in the time of COVID radical re-orderings of the way that bodies, space and time articulate with one another are taking place, and that this is of great ethnographic interest. 'Keeping in touch' and 'keeping up relations' across generations remain important objectives, but a metaphorical lag opens up between how we describe the doing of kinship and what it means to do it in practice. The crisis has, for me at least, brought the contours of mutuality into stark relief. To put it plainly, I want to hug my mother and I want to touch and hold my granddaughter and have her climb all over me, pulling my beard and poking me as she goes. It is in these deep and currently frustrated desires that one begins to understand the gulf that lies between intrinsic relation and technologically mediated extrinsic connection and to wonder what intimacy will look like when we eventually leave lockdown and social distancing behind.

Bов Simpson is a Professor of Anthropology at the University of Durham. His interests mainly lie in the anthropological study of bioethics, biomedicine and biotechnologies. His most recent monograph (coauthored with Salla Sariola) is Research as Development: Biomedicine, Collaboration and Bioethics in Sri Lanka (Cornell University Press, 2019).

E-mail: robert.simpson@durham.ac.uk

\section{References}

Howes, D. (2004), 'Hyperesthesia, or, the Sensual Logic of Late Capitalism', in The Empire of the Senses, (ed.)

D. Howes (London: Berg), 281-303.

Howes, D., (ed.) (2014), A Cultural History of the Senses in the Modern Age, 1920-2000, (London: Bloomsbury). 
Howes, D., (ed.) (2018), Senses and Sensation: Critical and Primary Sources, 2 Vols. (London: Bloomsbury).

Howes, D., and C. Classen (2014), Ways of Sensing: Understanding the Senses in Society (London: Routledge).

Montagu, A. (1986), Touching: The Human Significance of the Skin, 3rd Ed. (New York: HarperCollins).
Sahlins, M. (2013), What Kinship Is . . And is Not (Chicago: University of Chicago Press).

Strathern, M. (2020), Relations: An Anthropological Account (Durham, NC: Duke University Press). 